\title{
Presente y Porvenir de la Unesco
}

La experiencia de la Unesco (United Nations Scientific, Educational Cultural Organization) o sea la Organización para la Cultura, la Ciencia y la Educación de las Naciones Unidas puede tener vasta resonancia y gran utilidad si los países que la constituyen se resuelven a tomar el asunto en serio y dejar, en la trastienda, celos y rivalidades políticos, en aras a una provechosa obra de cooperación intelectual.

He dicho cooperación intelectual, y debo explicarme, porque hubo una institución de este nombre perteneciente a la finada Líga de las Naciones. La causa de su muerte no ha sido el deceso de su matriz sino que ya ella misma era difunta, desde antes, y arrastraba su cadáver con todas las apariencias de vitalidad, un tanto crepuscular, tal como esos cuerpos de ajusticiados o yíctimas de accidentes, que después de. sufrir el seccionamiento de la cabeza siguen moviéndose en virtud de incontenibles reacciones reflejas.

Había fallecido lapcooperacién Intelectuab de la Liga, por excesivo aparato gubernativo. Los monopolios oficiales tienen mucho de bueno y no poco de malo. Dé "estogrttimo haye más cuahabs se" trata de problemas de la inteligencia. Siendo tan libre, el espíritu rechaza la petrificación estatal. Por eso ni editoriales del Estado, ni literatura oficial, ni tutela gubernativa sirven de mucho, salvo procrear Zoilos, mentalidades de re petición, mas no en el sentido de los rifles, sino al revés: que los fusiles de repetición aligeran y aumentan en eficacià, en tanto que las inteli gencias de repetición son lentas y ganan en burocracia.

La Unesco puede ser una especie de UNRRA del espíritu, si los no devastados lo consienten. De sus dos finalidades principales -escla recer el espíritu, contribuyendo a fundar la paz en la cultura, y acudi a la rehabilitación del instrumental de cultura de los países arrasados por la guerra-, esta última es la que más interesa a un grupo de part1cipantes. La discusión del presupuesto de la Unesco lo evidenció. Inglaterra, Polonia, Yugoeslavia, China, Checoeslovaquia, Holanda, Noruegi, etc. defendían un presupuesto alto, de 10 millones de dólares; Estados 
Unidos, Canadá, Australia, México, Perú, Venezuela, estaban por un presupuesto más bajo: de casi 7 millones. Francia quiso transigir aumentando este último en un millón y medio exclusivamente para recons trucción. Creo que fué un gesto diplomático, puesto que Francia recibe, por vía particular, de instituciones e individuos privados de los Estados Unidos, mucho más de lo que podrían recibir por intermedio de la Unesco.

Sería absurdo y hasta cruel criticar el empeño de los países devastados. Sin embargo, deberían considerar que los de Indoamérica se encuentran en la condición de devastados permanentes por la incuria, el ogoísmo y la torpeza de sus clases gobernantes. El analfabetismo del continente, la falta de bibliotecas, la pobreza de museos, el ayuno do estímulos intelectuales, equivalen a una devastación constante, sistemática, tremenda.

Si nuestra situación pudiera ser mostrada, no dudo de que habría acuerdo unánime para apoyarnos y consideramos en una situación peculiar. Ahí es donde, como de costumbre, falta el consenso americano. De los 44 Estados que concurrieron a Londres, a la conferencia preliminar de la Unesco, en noviembre de 1945, sólo 30 asistieron a la Primera conferencia oficial, en París, un año después. Entre los 14 ausentes, por no haber ratificado a tiempo, por no haber depositado las ratificaciones a punto o por otras razones, figuran: Argentina, Uruguay, Chile. Colombia, Paraquay, Panamá, Costa Rica, Salvador, Cuba, Guatemala. Es muy difícil convericer por sucausencia y discutir con mutismo.

El asunto de lasjidiomas dectrabajo se fesolyión así mismo, en forma parcial, por idéntica circunstancia. Se planteó que en la Unesco rigierar las mismas reglas que en la ONU, ya que aquélla es una "specialized agency", o sea un organismo especializado de ésta. Además, tanto en la Bureau Internacional del Trabajo, como en el de Educación, el castellano es idioma oficial. Triunfó una moción previa presentada por In glaterra, en el sentido de que, además de los dos idiomas de trabajo -francés e inglés-fuese de la misma categoría el del país en donde se reuniese la conferencia general. Como México será la próxima sede, por esta vez el castellano será lengua de trabajo: sólo por esta vez, si los países de América no hacen pesar su número, su razón y su influencia. Veinte países, incluyendo a Filipinas, hispanoparlantes, o sea el 48 por ciento de la Unesco, con una población de no menos de $100 \mathrm{mí}$. llones de habitantes, sin contar los que hablan castellano en Estados Unidos, Brasil, la misma Francia, etc., deben usar su medio de expresión original. En este aspecto, disiento radicalmente del señor Javier 
Arango, delegado observador de Colombia, el cual, cuando discutíamos el artículo 33, en subcomisión, nos leyó unas elegantes cuartillas de su diario, y propuso lo que ya habían propuesto los britáánicos, en discordancia con lo que sosteníamos los demás indoamericanos. Válgale al amigo la excusa de haber llegado tarde a dicha reunión, cuando ya e! debate se hallaba sumamente avanzado. De paso, sentimos mucho que Colombia no tuviera voto. El sentimiento acreció cuando, al final de lá Conferencia, una mañana apareció en el local de la Unesco, Germán Arciniegas, recién llegado de Londres sin voz y sin voto, según en. tiendo...

Probablemente, en la próxima conferencia lleguemos a resultados más positivos. Para eso hace faita que estemos presentes, no comc bloque concertado, si se quiere, sino como realidad homogénea, lo que es inevitable. Al respecto, disiento de la opinión de un antiguo diplo. mático sudamericano, observador de su gobierno, quien rehusaba tercamente toda idea de "bloque continental". Acaso su práctica en organismos políticos, antes de la guerra número 2 , lo tenía corroído de escepticismo. Los tiempos han cambiado. Realidad y método permiten ser más optimistas.

¿Qué se propone la Unesco?

Sus fines pueden resumirse asi:

La respuesta ritual sería: fomentar y difundir la cultura en todos sus aspectos; propender al intercambio de conocimientos y de factores cul turales; vincular la cultura lalas masáse contribuirSa la rehabilitación cultural de los paises dēvastadosi cayeron bajo al égida totalitaria.

No entendemos la Unesco desde dicho ángulo ritualista. Padezco el mal de lo concreto. Me parece que la Primera Conferencia ha tenido amplio éxito por cuanto ha organizado los cuadros administrativos. de relaciones políticas, económicas y jurídicas de la Unesco, y tambiér. ha orientado ciertos trabajos. En la práctica, la reunión de París ha sido una toma de pulso y una preparación del marco. Se ha elaborado ei continente, con rara pericia e inaudita velocidad. Toca a la segunda conferencia perfeccionar y decantar el contenido.

En cuanto a éste, la Conferencia de París ha tenido poca relación con lo americano. Si bien, la sección Científica ha enfocado el proble ma del Amazonas, no ha tenido el tíno de convocar a una subcomisión especial con audiencia de Perú, Colombia, Brasil, países colindantes sino que se limitó a escuchar unos votos platónicos de un delegado brasileño. 
Verdad, también, que la culpa es de quienes nos mantuvimos ausentes del debate. Sin embargo, el pedido de consulta se imponía.

Mientras se discutió acerca de las bibliotecas europeas arrasadas, no se dijo nada de la también arrasada biblioteca nacional de Lima. De. sastre por desastre, la cultura sufre lo mismo cuando se destruyen Iibros bien por acción del fuego casual que del fuego de la guerra. Los libros perecen por identico modo, y los pueblos deben sufrir ayuno de conocimientos y recreaciones literarias.

Mas, lo positivo de la Unesco consiste en su propósito de organizar una cultura libre, democrática, popular, sin mengua de la de los sabios y sabihondos. La vinculación con las masas representa un fruto de la guerra número 2. El debate sobre "masa media" encarna una conquista de los tiempos. Los postulados sobre el libre acceso a la inform ción estrictamente visual que da el Cine, la auditiva que da la Radio y la visual-intelectiva que da la Lectura, significan otros tantos impactos en la mentalidad totalitaria que desenvolvieron los dictadores fascistas y sus congéneres pseudo-democráticos. La Unesco sobrepasa los lin. deros de una escueta cooperación intelectual para los selectos. Se ir. clina a recoger la cosecha de las generaciones sin averiguar quién sembró la simiente.

En tal punto، surgió el problema de la participación rusa. Según los periódicos satélites de los partidos comunistas norteamericanos, la Unes. co encarna un giqanitleskiposfuerzo dper potener una cultura dirigida por las grandes potencias. Ef respuesta, los partidarios de la Unesco, especialmente el "New ausencia de Rusia de la Unesco implica una primera razón de elogio. por cuanto desnuda la voluntad totalitaria de aquel país, reñido con la libertad de-información. Así se plantea un problema político nada ajeno a la futura vida de la Unesco.

No dudo yo de que Rusia intervendrá al final en la Unesco. Por ahora, su voz se hace escuchar mediante estados satélites o ceñidamente adictos. Además, si, de acuerdo con los postulados de la Unesco, se invita a pertenecer a ella a naciones que no forman entre los de la ONU. y aún a los antiguos totalitarios, al menos en ciertos ramos del saber, podría ocurrir un alineamiento de la cultura mundial, al que no podría ignorar Rusia, por potente que sea - y précisamente, menos por eso.

Para todo lo que haya que hacer en la Unesco se requiere, como cuestión previa, la organización de nuestras Comisiones Nacionales, y la constitución eficaz de nuestras delegaciones. En la Conferencia de Londres, sólo México y Guatemala se hicieron representar por sus Mi- 
nistros de Educación -hablo de América. Los demás países nuestros delegaron absurdamente su personería en funcionarios consulares y diplomáticos, sin ningún vínculo con la cultura. Europa, Asia y los Estados Unidos destacaron a sus hombres de letras y ciencias mejor calificados. Bastará recordar que Archibald Mac Beisch, León Blum, Julien Huxley, Julien Cain, figuraron en el elenco de representantes a la Unesco. Junto a ellos la meritoria, pero inútil voz del señor Cónsul Fulano de Tal resulta de criminal ineficacia.

De idéntico modo, las comisiones nacionales deben representar algo fundamental. Algo auténtico. No se prescinda de Mengano por enemigo político, si culturalmente vale. Pero, no se invente valor cultural como decoración del servicio político. Alguna vez habremos de hacer las cosas en serio. La Unesco evidenció su buen sentido cuando, sin desgarramientos ni discursos, obligó a desistir a quienes la sostenían, de la candidatura de Francis Biddle a la dirección del organismo. Biddle, que ha sido Fiscal de los Estados Unidos y como tal miembro del Gabinete de F. D. Roosevelt, que pertenece a la Corte Suprema, que ha presidido el tribunal de Nurenberg/ posee muchos valores, pero no un científico o un intelectual en el más amplio sentido de la palabra. Pertenece a la política y al foro antes que a la ciencia, la literatura, el arte, la edicación. La lección que de ello fluye puede ser aprovechada por todos los países que han ratificado el pacto de la Unesco. A los sudamericanos nos será más útil que a nadie, en vista de nuestra consuetudinaria inclinación al éxito fácil Yal mérito recogido en eualquier parte.

$$
\text { "Jorge Puccinelli Converso» }
$$

París, 20 de diciembre de 1946.

Luis Alberto Sánchez. 